\title{
CrimRxiv
}

\section{Recruitment into Organized Crime: An Agent-Based Approach Testing the Impact of Different Policies}

Francesco Calderoni, Gian Maria Campedelli, Aron Szekely, Mario Paolucci, Giulia Andrighetto

Published on: Feb 23, 2022

DOI: $10.21428 / \mathrm{cb} 6 a b 371 . d 3 c b 86 \mathrm{db}$

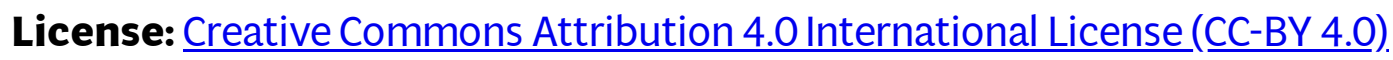


